\title{
Underuse of medication for circulatory disorders among unmarried women and men in Norway?
}

\author{
Øystein Kravdal ${ }^{1,2,4^{*}}$ and Emily Grundy ${ }^{3}$
}

\begin{abstract}
Background: It is well established that unmarried people have higher mortality from circulatory diseases and higher all-cause mortality than the married, and these marital status differences seem to be increasing. However, much remains to be known about the underlying mechanisms. Our objective was to examine marital status differences in the purchase of medication for circulatory diseases, and risk factors for them, which may indicate underuse of such medication by some marital status groups.

Methods: Using data from registers covering the entire Norwegian population, we analysed marital status differences in the purchase of medicine for eight circulatory disorders by people aged 50-79 in 2004-2008. These differences were compared with those in circulatory disease mortality during 2004-2007, considered as indicating probable differences in disease burden.

Results: The unmarried had 1.4-2.8 times higher mortality from the four types of circulatory diseases considered. However, the never-married in particular purchased less medicine for these diseases, or precursor risk factors of these diseases, primarily because of a low chance of making a first purchase. The picture was more mixed for the divorced and widowed. Both groups purchased less of some of these medicines than the married, but, especially in the case of the widowed, relatively more of other types of medicine. In contrast to the never-married, divorced and widowed people were as least as likely as the married to make a first purchase, but adherence rates thereafter, indicated by continuing purchases, were lower.

Conclusion: The most plausible interpretation of the findings is that compared with married people, especially the never-married more often have circulatory disorders that are undiagnosed or for which they for other reasons underuse medication. Inadequate use of these potentially very efficient medicines in such a large population group is a serious public health challenge which needs further investigation. It is possible that marital status differences in use of medicines for circulatory disorders combined with an increasing importance of these medicines have contributed to the widening marital status gap in mortality observed in several countries. This also requires further investigation.
\end{abstract}

Keywords: Norway, Circulatory disorders, Marital status, Medication, Underuse, Register data

\section{Background}

Numerous studies from many different countries have shown that married people have lower all-cause mortality than the unmarried and lower mortality from several specific causes and cause groups, including circulatory diseases [1-3]. Health-related and other types of selection to and from marriage are known to play a role in this differentiation [4], but marriage is also considered to

\footnotetext{
* Correspondence: okravdal@econ.uio.no

${ }^{1}$ Norwegian Institute of Public Health, Oslo, Norway

2Department of Economics, University of Oslo, Oslo, Norway

Full list of author information is available at the end of the article
}

have health protective effects. These include economic benefits [5], social support, social control by a spouse $[6,7]$ and, partly because of this social control, a lower propensity for risky behaviours [8-10]. These factors may affect health partly through differences in healthrelated behaviours more generally, including participation in screening programmes, medical consultation rates and adherence to medication, all of which would potentially lead to differences in medication use.

Our aim in this paper is to see whether there are differences by marital status in the purchase (encashment) 
of prescribed drugs for eight types of circulatory disorders. We also consider incident and continuing purchase of these medicines. These marital status differences in medication purchase (assumed to be indicative of medication use) are compared with marital status differences in mortality from four specific circulatory causes, used as an indicator of probable differences in disease burden. We use data from registers that cover the entire Norwegian population, and in particular the Norwegian Prescription Database, which includes all purchases of prescription medicine since 2004. The analysis covers the years 2004-2008.

Circulatory diseases are the most common group of causes of death in high income countries, so such an analysis of marital status differentials in the use of medicines for these diseases and their risk factors is potentially very important from a public health perspective. This is particularly the case in the context of improvements in the efficacy of therapeutic treatments for circulatory diseases. Advances in drug-based and surgical treatments have been found to matter greatly at the population level $[11,12]$ and perhaps explain $1 / 4$ to $1 / 2$ of the reduction in the mortality from circulatory diseases over a couple of decades from about 1980 [13-15], and an American study showed that many years of life are lost because a large proportion of the population receive inadequate treatment for coronary heart diseases [16]. Analyses of differentials in medication use by marital status may thus also shed light on recent increases in marital status differentials in circulatory disease mortality, which have contributed strongly to the increases in the corresponding all-cause mortality differentials observed in a number of countries [17-19]. In Norway, especially the never-married have experienced a rising excess mortality compared to the married [17].

Previous research on marital status differentials in medication use is sparse and inconclusive. Delayed diagnosis or treatment for cardiovascular problems among unmarried groups has been reported in some studies $[20,21]$, which accords with studies showing that unmarried people are often diagnosed later with cancer $[22,23]$ and have lower participation rates in screening for various diseases [24]. Differences in adherence to treatments for various diseases by marital status and availability of social support have also been reported. For example, some studies have shown that unmarried people are less likely to follow doctors' advice about medication after diagnosed coronary diseases [25-28] or hypertension [29], and adverse changes in health care utilisation among recently widowed chronically ill men have been reported as well [30]. However, other recent studies of adherence to treatment for circulatory diseases or conditions (risk factors) have not found marital status differences $[31,32]$. Moreover, the evidence - in either direction - is generally relatively weak because of small sample sizes
[28,29,31] and possible bias arising from use of selfreported measures of medication adherence [25,29,31], rather than measures from prescription registers [32] or electronic monitoring [28].

\section{Methods \\ Data}

The study is based on analysis of two data files, constructed (in 2009-2012) from various Norwegian population registers. Both include, for everyone who has lived in Norway since 1960, year of death, immigration and emigration (if any) and marital status and educational level at the beginning of each year (since 1980, though only the information for the years after 2004 was used in the analysis). These variables were taken from the Central Population Register and the Educational Database (operated by Statistics Norway). Additionally, one of the files includes information from the Cause-of-death Register (up to 2007), while the other includes information from the Norwegian Prescription Database (NorPD) for 2004-2008. NorPD covers all purchases of prescription medicine (defined by Anatomical Therapeutic Chemical (ATC) classification) since 2004 by Norwegian residents, except individuals living in institutions [33]. Because of the latter exclusion, we restricted our analysis to persons younger than 80 during the period under study. The lowest age considered is 50 . While circulatory diseases occur among younger individuals, and are treated medically, there are few deaths from this cause group at these lower ages.

Separate analyses were undertaken for women and men, as several studies have suggested that some of the health benefits of partnership may be sex-specific, especially in older age groups $[34,35]$. In all models, we controlled for level of education, which is an important determinant of marriage and divorce $[36,37]$ as well as health [38] and health care use [39]. Age was, of course, also controlled for.

The use of register data for this research purpose has been approved by the Regional Committees for Medical and Health Research Ethics and the Norwegian Data Protection Authority.

\section{Mortality analysis}

Discrete time hazard models for all-cause and causespecific mortality were estimated for the period 20042007, following standard procedures [40]. A series of oneyear observations was constructed, starting in January 2004, for all those then aged 49-78 and living in the country. The last observation was the year of death, the year the person turned 79, the year of emigration, or 2007, whichever came first. Those who became 50 or immigrated during the observation period were added from January of the year of their $50^{\text {th }}$ birthday or the 
year after immigration, respectively. Observations were excluded if the person lived temporarily abroad at the beginning of the year. Logistic models were estimated from all remaining observations. In total, there were 35,174 deaths within 2,602,246 person-years of observation among men and 23,970 deaths within 2,693,670 person-years of observation among women. Table 1 shows the distribution of these by marital status.

The specific causes of death considered are ischemic heart diseases (ICD-10 codes I00-I25), other heart diseases (I26-I52), cerebrovascular diseases (I60-I69) and all other circulatory diseases (other I00-199).

\section{Analyses of medicine purchases: prevalence, incidence and discontinuation}

In the analysis of drug purchases we considered eight groups of drugs, defined by Kuo et al. [41] as indicating treatment for specific disorders. These disorders were (ATC codes shown in notes to Table 2): i) coronary and peripheral vascular diseases treated with platelet aggregation inhibitors, ii) coronary and peripheral vascular diseases treated with anticoagulants, iii) hypertension without any diagnosed heart disease, iv) hyperlipedemia, v) arrhythmic cardiac diseases, vi) angina, vii) congestive heart failure (usually in combination with hypertension), and viii) other ischemic heart diseases (usually in combination with hypertension). The analysis included three steps. First, logistic models for the chance of purchasing certain drugs at least once during 2004-2008 (i.e. prevalence of medication purchase and, presumably, use) were estimated, conditional on living in the country at the beginning and end of that period. There were 579,218 observations for men and 620,911 for women.

In the second step, discrete-time hazard models for the chance of starting to purchase the specific type of drug (i.e. incidence) were estimated for those who did not use it in 2004. More specifically, one-year observations from 2005 were created conditioned on the individual being of age 50-79 that year, being alive both at the start and the end of the year and not yet having started to purchase the medicine by the beginning of the year. The outcome variable was whether the drug was purchased at least once during the year.

Similarly, in the third step, discrete-time hazard models for discontinuing the purchase of the medicine were estimated. One-year observations from 2005 were created conditioned on the individual being of age 50-79 that year, being alive both at the start and the end of the year, having purchased the medicine at least once during the preceding year, but having had no earlier discontinuation of the purchase of that medicine (i.e. the individual has either purchased the medicine in every year from 2004 to the preceding year, or started in 2005 or later and kept purchasing until at least the previous year). The outcome variable was whether the drug was purchased at least once during the year. For simplicity, the signs of the effects are reversed in the tables and can thus be interpreted as effects on continuation rather than discontinuation.

\section{Results}

\section{Marital status differences in mortality from circulatory} diseases

Mortality from circulatory disease was more than twice as high among the never-married as among the married for both men and women. For all circulatory diseases combined the odds ratio for men was 2.11 (95\% CI 1.99$2.23)$ and that for women $2.37(2.15-2.61)$. Odds ratios for men and women varied between 1.94 and 2.84 across the four main sub-categories of circulatory diseases considered (Table 2). For men the estimates were 1.93-2.52 for the divorced and 1.51-1.75 for the widowed. Similar results were seen for women, with odds ratios of 1.632.14 for the divorced, and 1.44-1.66 for the widowed.

\section{Associations between marital status and purchase of medication 2004-2008}

Never-married men and women were generally less likely than the married to purchase medicine for circulatory disorders (Table 2 and signs shown in Panel A of Table 3). The only exceptions were that there was no significant

Table 1 Number of deaths and person-years of exposure in the mortality analysis of women and men aged 50-79 in 2004-2007, by marital status

\begin{tabular}{|c|c|c|c|c|}
\hline & Never-married & Married & Widowed & Divorced/separated \\
\hline \multicolumn{5}{|l|}{ Men } \\
\hline Number of deaths from all causes & 5325 & 19995 & 3321 & 6533 \\
\hline Number of deaths from all circulatory diseases & 1679 & 6031 & 1145 & 2025 \\
\hline Person-years of exposure & 277508 & 1818415 & 99705 & 406618 \\
\hline \multicolumn{5}{|l|}{ Women } \\
\hline Number of deaths from all causes & 2027 & 10515 & 7490 & 3938 \\
\hline Number of deaths from all circulatory diseases & 509 & 2248 & 2262 & 829 \\
\hline Person-years of exposure & 175001 & 1670393 & 400626 & 447650 \\
\hline
\end{tabular}


Table 2 Effects of marital status on all-cause and cause-specific mortality (ICD-10 codes in parentheses) 2004-2007 and the chance of purchasing various types of medicines for circulatory disorders 2004-2008 among women and men aged $50-79^{b}$

\begin{tabular}{|c|c|c|c|c|c|}
\hline & & \multicolumn{3}{|c|}{$\begin{array}{l}\text { Effects of marital status } \\
\text { (with } 95 \% \text { confidence intervals) }\end{array}$} & \multirow{2}{*}{$\begin{array}{c}\text { Number of deaths } \\
\text { or persons } \\
\text { purchasing } \\
\text { the medicines }\end{array}$} \\
\hline & & Never-married & Widowed & $\begin{array}{l}\text { Divorced/ } \\
\text { separated }\end{array}$ & \\
\hline \multicolumn{6}{|l|}{ Men } \\
\hline \multirow[t]{6}{*}{ Mortality from } & All causes & $2.05^{* * *}(1.98-2.11)$ & $1.56^{* * *}(1.50-1.62)$ & $1.96^{* * *}(1.91-2.02)$ & 35174 \\
\hline & All circulatory diseases (100-199) & $2.11^{* * *}(1.99-2.23)$ & $1.65^{* * *}(1.54-1.75)$ & $2.08^{* * *}(1.97-2.18)$ & 10880 \\
\hline & Ischemic heart diseases (120-125) & $1.94^{* * *}(1.80-2.10)$ & $1.67^{* * *}(1.52-1.82)$ & $1.93^{* * *}(1.80-2.07)$ & 5737 \\
\hline & Other heart diseases (I26-152) & $2.71^{* * *}(2.39-3.08)$ & $1.63^{* * *}(1.52-1.82)$ & $2.52^{* * *}(2.24-2.85)$ & 1809 \\
\hline & Cerebrovascular diseases (160-169) & $1.99^{* * *}(1.75-2.26)$ & $1.51^{* * *}(1.31-1.74)$ & $2.07^{* * *}(1.84-2.33)$ & 2066 \\
\hline & Other circulatory diseases & $2.13^{* * *}(1.81-2.50)$ & $1.75^{* * *}(1.46-2.10)$ & $2.11^{* * *}(1.82-2.10)$ & 1268 \\
\hline \multirow[t]{8}{*}{$\begin{array}{l}\text { Purchase of medication } \\
\text { for }\end{array}$} & $\begin{array}{l}\text { Coronary and peripheral vascular } \\
\text { diseases, antiplatelet }{ }^{c}\end{array}$ & $0.70^{* * *}(0.68-0.73)$ & $1.00(0.95-1.05)$ & $1.02(0.99-1.05)$ & 42780 \\
\hline & $\begin{array}{l}\text { Coronary and peripheral vascular } \\
\text { diseases, anticoagulant }{ }^{d}\end{array}$ & $0.88^{* * *}(0.85-0.91)$ & $1.04^{*}(1.00-1.08)$ & $1.03^{* *}(1.00-1.06)$ & 59898 \\
\hline & Hypertension ${ }^{e}$ & $0.98(0.95-1.01)$ & $1.10^{* * *}(1.06-1.15)$ & $0.97^{* * *}(0.94-0.99)$ & 56019 \\
\hline & Hyperlipedemia $^{f}$ & $0.69^{* * *}(0.68-0.71)$ & $0.95^{* * *}(0.93-0.98)$ & $0.89^{* * *}(0.87-0.90)$ & 185023 \\
\hline & Anti-arrhythmic cardiac diseases ${ }^{9}$ & $1.02(0.97-1.08)$ & $1.09^{* * *}(1.03-1.16)$ & $1.09^{* * *}(1.04-1.14)$ & 18204 \\
\hline & Ischemic heart diseases/angina ${ }^{\text {h }}$ & $0.75^{* * *}(0.73-0.78)$ & $0.98(0.94-1.02)$ & $0.99(0.97-1.02)$ & 65918 \\
\hline & Congestive heart failure/hypertension ${ }^{i}$ & $0.92^{* * *}(0.90-0.94)$ & $1.10^{* * *}(1.07-1.32)$ & $0.96^{* * *}(0.95-0.98)$ & 195657 \\
\hline & Other ischemic heart diseases/hypertension & $0.88^{* * *}(0.86-0.90)$ & $1.08^{* * *}(1.05-1.11)$ & $0.96^{* * *}(0.94-0.97)$ & 198133 \\
\hline \multicolumn{6}{|l|}{ Women } \\
\hline \multirow[t]{6}{*}{ Mortality from } & All causes & $2.05^{* * *}(1.95-2.15)$ & $1.40^{* * *}(1.35-1.44)$ & $1.70^{* * *}(1.64-1.77)$ & 23970 \\
\hline & All circulatory diseases (100-199) & $2.37^{* * *}(2.15-2.61)$ & $1.53^{* * *}(1.44-1.62)$ & $1.83^{* * *}(1.69-1.98)$ & 5848 \\
\hline & Ischemic heart diseases (120-125) & $2.38^{* * *}(2.05-2.77)$ & $1.44^{* * *}(1.31-1.59)$ & $1.80^{* * *}(1.59-2.04)$ & 2323 \\
\hline & Other heart diseases (I26-152) & $2.84^{* * *}(2.30-3.50)$ & $1.66^{* * *}(1.44-1.90)$ & $2.14^{* * *}(1.79-2.56)$ & 1163 \\
\hline & Cerebrovascular diseases (160-169) & $2.18^{* * *}(1.82-2.61)$ & $1.51^{* * *}(1.35-1.69)$ & $1.63^{* * *}(1.40-1.91)$ & 1678 \\
\hline & Other circulatory diseases & $1.94 * * *(1.43-2.64)$ & $1.63^{* * *}(1.36-1.95)$ & $1.91 * * *(1.36-1.95)$ & 684 \\
\hline \multirow[t]{8}{*}{$\begin{array}{l}\text { Purchase of medication } \\
\text { for }\end{array}$} & $\begin{array}{l}\text { Coronary and peripheral vascular diseases, } \\
\text { antiplatelet }{ }^{c}\end{array}$ & $0.84^{* * *}(0.78-0.90)$ & $1.12^{* * *}(1.08-1.16)$ & $1.24^{* * *}(1.19-1.29)$ & 22058 \\
\hline & $\begin{array}{l}\text { Coronary and peripheral vascular diseases, } \\
\text { anticoagulant }^{\mathrm{d}}\end{array}$ & $0.92^{* * *}(0.88-0.96)$ & $1.07^{* * *}(1.04-1.10)$ & $1.08^{* * *}(1.05-1.11)$ & 51264 \\
\hline & Hypertension $^{e}$ & $0.96 *(0.93-1.00)$ & $1.03^{* * *}(1.01-1.06)$ & $0.94^{* * *}(0.92-0.97)$ & 58882 \\
\hline & Hyperlipedemia $^{f}$ & $0.78^{* * *}(0.77-0.81)$ & $0.95^{* * *}(0.94-0.97)$ & $0.92^{* * *}(0.91-0.94)$ & 175477 \\
\hline & Anti-arrhythmic cardiac diseases ${ }^{9}$ & $1.00(0.92-1.09)$ & $1.08^{* * *}(1.03-1.13)$ & $1.07^{* *}(1.01-1.14)$ & 11746 \\
\hline & Ischemic heart diseases/angina ${ }^{\text {h }}$ & $0.85^{* * *}(0.82-0.89)$ & $1.11^{* * *}(1.08-1.13)$ & $1.20^{* * *}(1.16-1.23)$ & 52641 \\
\hline & Congestive heart failure/hypertension ${ }^{i}$ & $0.95^{* * *}(0.93-0.97)$ & $1.07^{* * *}(1.06-1.09)$ & $0.99(0.97-1.01)$ & 203305 \\
\hline & Other ischemic heart diseases/hypertension ${ }^{j}$ & $0.87^{* * *}(0.85-0.89)$ & $1.03^{* * *}(1.01-1.04)$ & $0.94^{* * *}(0.92-0.95)$ & 187899 \\
\hline 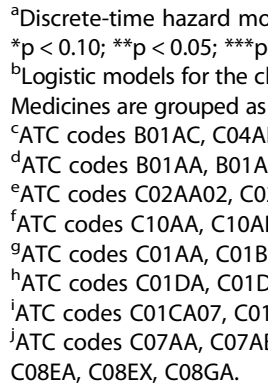 & $\begin{array}{l}\text { dels are estimated. The models also include age } \\
<0.01 \text {. } \\
\text { lance of purchasing the medicines are estimated. } \\
\text { in Kuo et al. [41]. See details in notes C-j. } \\
003 \text { (except B01AC06, B01AC08, B01AC09, B01A } \\
3, B 01 A D, B 01 A X \text {. } \\
\text { AB02, C02AC, C02BA, C02BB, C02CA, C02CC, C0 } \\
\text {, C10AC, C10AD, C10AX, C10BA, C10BX. } \\
\text {, C01BB, C01BC, C01BD, C01BG, C01EB10. } \\
\end{array}$ & $\begin{array}{l}\text { e-year groups), year } \\
\text { odels also include age } \\
1 \mathrm{AC} 15, \mathrm{~B} 01 \mathrm{AC} 19, \mathrm{BO} \\
02 \mathrm{DB}, \mathrm{C} 02 \mathrm{DD}, \mathrm{C} 02 \mathrm{DC}\end{array}$ & $\begin{array}{l}\text { (in one-year groups) } \\
\text { (in five-year groups) } \\
1 \mathrm{AC21} \text { ). } \\
\mathrm{G}, \mathrm{C} \text { ) }\end{array}$ & $\begin{array}{l}\text {, and educational lev } \\
\text { ) and educational leve } \\
3 \mathrm{AX}, \mathrm{C03DA}, \mathrm{C03DB} \text {, }\end{array}$ & $\begin{array}{l}\text { el (in five categories). } \\
\text { I (in five categories). } \\
\text { C02L. }\end{array}$ \\
\hline
\end{tabular}


Table 3 Sign and significance (+ and - meaning $p<0.10 ;++$ and - - meaning $p<0.05 ;+++$ and - - meaning $p<0.01$ ) of effects of marital status on the chance of purchasing medicine in 2004-2008, the chance of starting to purchase medicine 2005-2008, and the chance of continuing with the medicine purchases 2005-2008

\begin{tabular}{|c|c|c|c|c|c|c|c|}
\hline & & $\begin{array}{l}\text { Men } \\
\text { Never- } \\
\text { married }\end{array}$ & Widowed & $\begin{array}{l}\text { Divorced/ } \\
\text { separated }\end{array}$ & $\begin{array}{l}\text { Women } \\
\text { Never- } \\
\text { married }\end{array}$ & Widowed & $\begin{array}{l}\text { Divorced/ } \\
\text { separated }\end{array}$ \\
\hline \multicolumn{8}{|c|}{ Panel A: Purchase of medicine in 2004-2008 (signs as in estimates in Table 2) } \\
\hline \multicolumn{2}{|l|}{ Coronary and peripheral vascular diseases, antiplatelet } & -- & & & --- & +++ & +++ \\
\hline \multicolumn{2}{|l|}{ Coronary and peripheral vascular diseases, anticoagulant } & --- & + & ++ & --- & +++ & +++ \\
\hline \multicolumn{2}{|l|}{ Hypertension } & & +++ & -- & - & +++ & -- \\
\hline \multicolumn{2}{|l|}{ Hyperlipedemia } & --- & --- & -- & -- & -- & -- \\
\hline \multicolumn{2}{|l|}{ Anti-arrhythmic cardiac diseases } & & ++ & ++ & & +++ & ++ \\
\hline \multicolumn{2}{|l|}{ IHD/Angina } & --- & & & --- & +++ & +++ \\
\hline \multicolumn{2}{|l|}{ Congestive heart failure/hypertension } & --- & +++ & -- & --- & +++ & \\
\hline \multicolumn{2}{|l|}{ Other IHD/hypertension } &.- & +++ & -- & $-\cdots$ & +++ & $-\cdots$ \\
\hline \multicolumn{8}{|c|}{ Panel B: Starting and continuing purchase of medicine $2005-2008^{a}$} \\
\hline \multirow{2}{*}{ Coronary and peripheral vascular diseases, antiplatelet } & Start & -- & & +++ & $-\cdots$ & +++ & +++ \\
\hline & Continuation & ++ & & & +++ & & +++ \\
\hline \multirow{2}{*}{ Coronary and peripheral vascular diseases, anticoagulant } & Start & -- & & +++ & & +++ & +++ \\
\hline & Continuation & & & -- & + & & \\
\hline \multirow{2}{*}{ Hypertension } & Start & & +++ & & - & ++ & - \\
\hline & Continuation & +++ & & -- & ++ & &.- \\
\hline \multirow{2}{*}{ Hyperlipedemia } & Start & --- & & & --- & -- & - \\
\hline & Continuation & --- & --- & -- & & -- & -- \\
\hline \multirow{2}{*}{ Anti-arrhythmic cardiac diseases } & Start & & +++ & +++ & & +++ & +++ \\
\hline & Continuation & +++ & & -- & & & \\
\hline \multirow{2}{*}{ IHD/Angina } & Start & $-\cdots$ & & & $-\ldots$ & +++ & +++ \\
\hline & Continuation & +++ & & & +++ & + & \\
\hline \multirow{2}{*}{ Congestive heart failure/hypertension } & Start & -- & +++ & +++ & & +++ & ++ \\
\hline & Continuation & $--\cdot$ & --- & -- & $-\cdots$ & -- & -- \\
\hline \multirow{2}{*}{ Other IHD/hypertension } & Start & -- & +++ & +++ & -- & +++ & ++ \\
\hline & Continuation & & $-\ldots$ &.- & & &.- \\
\hline
\end{tabular}

${ }^{a}$ Discrete-time hazard models are estimated. The models also include age (in five-year groups), year (in one-year groups), and educational level (in five categories).

association between being never-married and purchasing medicine for hypertension (alone) or arrhythmic diseases. For both sexes, the sharpest negative effects were seen with respect to drugs for hyperlipidemia.

Among divorced men and women, the purchase of four types of medicine was lower than in the married reference group. These were medication for hypertension (alone), hyperlipidemia, heart failure (among men), and ischemic heart disease. On the other hand, three types of medicine were purchased to a larger extent by the divorced than the married, for one or both sexes: medicine for coronary and peripheral vascular diseases (antiplatelet as well as anticoagulant treatment), arrhythmic diseases and angina. However, with two exceptions (1.20 and 1.24), the positive estimates were not above 1.10 .
The widowed were, on the whole, more likely than the married to purchase medicine for circulatory disorders. There was only one negative relationship: the use of medicine for hyperlipidemia. Relationships with respect to several other disorders were positive: hypertension, arrhythmic diseases, heart failure and ischemic heart disease for both sexes and coronary and peripheral vascular diseases and angina for women. Again, the positive relationships were not large; all effects were smaller than 1.12.

\section{Associations between marital status and starting and continuing drug purchase}

The lower chance of purchasing medicine among the never-married reflects a lower chance of making a first purchase (Table 3, Panel B). Once initiated, the chance of continuing to purchase the medication was significantly 
higher than (at a 5\% level) or as high among the nevermarried as the married for several disorders, exceptions being heart failure and, for men, hyperlipedemia.

For the divorced, who generally purchased about as much medicine for circulatory disorders as the married, there is an almost opposite pattern. Their chance of starting to purchase medicine was quite high. This was seen for several types of medicine for both men and women, and no effect runs in the other direction. On the other hand, they had a relatively low probability of continuing to purchase several types of the medicines considered, and there was only one example of the opposite.

The pattern for the widowed was similar to that for the divorced: there were several positive associations with the chance of starting to purchase medicine and one negative (as opposed to none for the divorced), and there was no positive association with the chance of continuing the purchases (as opposed to one for the divorced) and several negative ones. However, there were fewer of the latter associations (five in total, for three different conditions, as opposed to 10 in total for the divorced), so on the whole, the widowed appear to be less different from the married than are the divorced.

\section{Discussion}

These results show, consistent with other studies, large marital status variations in mortality from circulatory diseases with the highest risks, relative to married people, for the never-married followed by the divorced and then the widowed. Overall, in the age group considered here (50-79), the unmarried had rates of mortality from circulatory diseases 1.4-2.8 times higher than those of the married. However, never-married people in particular purchased less of the medicines that are typically used after such a circulatory disease has been diagnosed or risk factors for it identified. This was primarily because of a significantly lower chance of first purchase of most of these medicines The picture is more mixed for the divorced and widowed, who purchased less of some of these medicines but more of others, though the difference in the latter direction, which was seen especially among the widowed, was quite small (but statistically significant). In contrast to the never-married, the chances of starting to purchase these medicines were as least as high among the divorced and widowed as among married people, but adherence rates thereafter, indicated by continuing medication purchases, were lower (especially among the divorced).

We assume that purchases of medication are good measures of actual use of medication, and therefore refer to use in the remaining discussion. To the extent that there is a difference between purchase and use, it would seem likely, if anything, that the unmarried might be less inclined than the married to use the purchased medication, because of the lack of social support and control by a spouse that is further discussed below. If so, marital status differences in actual use may be more pronounced than suggested by our analysis of purchases.

\section{Interpretations of the observed patterns: underuse of medication?}

To draw conclusions about underuse of medicine one should ideally compare actual use with need or recommended use. Unfortunately, we lack information on the actual prevalence and severity of the various circulatory disorders (and associated risk factors), which would be good indications of the need, and must instead compare differences in medication purchase, reflecting medication use, with those in mortality. As mentioned, one of our key findings is that the never-married use less medicine than the married for all disorders considered except a few. In theory, it is possible that they also need less of these medicines, despite their much higher mortality from all circulatory disease groups (and thus presumably also from the disorders under consideration). Let us assume that they to a larger extent than the married suffer from the most severe types of each of these disorders, but have a lower prevalence of the less severe types for which medication is nevertheless recommended. Then, even if they take medicine in accordance with recommendations or needs (i.e. no underuse), they could end up using less medicine than the married and have higher mortality. In other words, low usage coupled with high mortality does not necessarily mean underuse.

However, this situation seems improbable especially as there are common risk factors for many less and more serious conditions and evidence from numerous studies points to a higher, rather than lower, prevalence of circulatory diseases and associated risk factors among the unmarried than the married. More specifically, it has been shown that the unmarried have higher cholesterol levels than the married [42], higher prevalence of diabetes [43,44], and higher blood pressure [42,45-47], although other studies do not point so clearly in this direction [48-52]. A modest excess prevalence of stroke among the unmarried has also been reported [52,53], as well as an excess prevalence of heart failure [54]. Consistent with this, other studies have reported that lifestyle factors associated with higher circulatory disease risks are less common among married people. In particular, the unmarried are more likely than the married to be physically inactive [42,49,50] (but see [55] for an opposite result), to be obese $[49,50,56]$, (but see [55] for an opposite result) to have a high intake of sodium [46], to eat more fast food $[55]$ and to smoke $[42,43,49]$.

Theoretically, the never-married could also have a lower prevalence of both the more and the less severe types of any disorder - thus taking less medicine even without any underuse - and still have a strong mortality disadvantage because of less adequate use of other types 
of treatment, such as angioplasty or bypass surgery. However, a study by Bearden et al. [57] that addressed the latter issue did not show any relationship between marital status and these kinds of surgical interventions. To conclude, we think the most plausible interpretation of our findings is that the unmarried, and especially the never-married, suffer from circulatory disorders to a larger extent than the married and therefore have a greater need for medication, but that they are on the whole less likely than the married to take the medication they need, which adds further to their mortality disadvantage.

If the unmarried are particularly inclined to use less medicine than recommended or needed for their circulatory disorders, the implications for mortality depend on whether this underuse is most pronounced with respect to the less severe or the more severe types of the disorder. The use of statins (for hyperlipidemia) may serve as a particularly relevant example. This drug is used both as primary prevention (i.e. in the absence of actual circulatory diseases and even at rather low cholesterol levels if other risk factors are identified) and secondary prevention (i.e. when a circulatory disease is diagnosed and presumably treated). The efficacy of this primary prevention has been highly disputed, though a recent Cochrane review pointed towards a mortality reduction [58], which would justify continuation of the practice. We have found that the married use more of this medicine than all groups of unmarried, despite the evidence summarised above that suggests higher cholesterol levels for the unmarried and thus more need for this medicine. Hypothetically, however, it could be that use of statins among the unmarried for the purposes of secondary prevention is consistent with their needs - and so higher than use among the marriedwhereas use for the purposes of primary prevention is much lower. Such a pattern would have fewer implications for mortality risks than a lower than recommended use for secondary prevention.

Finally, it should be noted that, if the unmarried to a larger extent than the married take too little medicine compared to their needs, they may of course still use somewhat more medicine per person. For example, we have found that some groups of unmarried use more medicine for arrhythmic diseases than the married, and no group less, which may reflect that there is a particularly large difference between the married and the unmarried in the actual prevalence of that disorder. The fact that mortality from "cardiovascular diseases other than ischemic heart diseases" varies particularly much according to marital status lends some support to this idea. Similarly, the unmarried use more diuretics for heart failure (a subgroup of medicines for that disease and not shown in the tables), alone or in combination with other medicine, and this may indicate a relatively high prevalence of right-sided heart failure, which may be linked to chronic obstructive pulmonary disease and thus smoking - the latter being more common among the unmarried according to some studies as already noted $[42,43,49]$.

\section{Factors underlying the differentials in use, and likely underuse, of medication}

As mentioned above, studies of marital status differences in health and mortality consistently refer to economic benefits of marriage and the important role played by spouses in providing social support and exerting social control [5-7]. Such factors are thought to affect the disease or accident incidence - through lifestyle (including the use of explicit preventive strategies) - as well as the availability of care, use of medical treatment and other factors of importance for the further development of the diseases. The pathway of special relevance given our perspective is that a spouse's encouragement and monitoring - but perhaps not the more favourable economic position of the married may affect the chance of seeking a consultation, receiving a diagnosis (or identifying risk factors) and prescription, cashing the initial prescription, and seeking and cashing further prescriptions. The reason for the probably modest importance of economic resources is that costs of prescriptions are typically not very high and for those with chronic diseases, there are subsidies as well as a cap on total annual expenses in Norway.

The evidence on such causal pathways is not large, but some studies of cardiovascular diseases suggest that spouses may encourage attendance at screening, prompt consultation after onset of symptoms or otherwise increase the chance of an early diagnosis [20,21]. Consistent with this, other studies have shown that the unmarried are often diagnosed later with cancer [22,23] and have lower participation rates in screening for various diseases [24]. Some, but not all, earlier investigations have also shown a poorer treatment adherence among the unmarried within rather small patient samples and often based on self-reporting of drug use [26-28,31,32,59], see details in Introduction. One recent very large study found no differences between partnered and unpartnered women in reported use of common medications for IHD two years after first hospital admission for this condition [60], but it may be that differences in adherence are less marked for severe conditions which have resulted in acute admissions.

In the absence of a spouse, children may play a similar role in supporting consultation and treatment adherence, and as fewer of the never-married than the widowed or divorced have children, this might account for some of the differences we found between groups of the unmarried when it comes to the chance of using and starting to use the medicines for circulatory disorders. However there is little evidence from previous studies on this issue. Another possible reason for these 
differences between the never-married and formerly married is that the latter may persist with habits of health care seeking developed during their married life, though it is harder to understand why they are more inclined to discontinue the use of medicines.

\section{Limitations and strengths of the analysis}

The study has some limitations, the most important being the lack of information on actual disorders as discussed above. Furthermore, formal marital status does not tell us the full story about actual living arrangements. Some of the unmarried live in cohabiting unions (currently $29 \%$ in the age group $45-66$ and $10 \%$ in the age group 67-79, according to Statistics Norway [61]), and if cohabitants use medicine to a larger extent than the unmarried who live alone and do not have a partner, the difference between the latter and the married will be even larger than the estimated difference between the unmarried and the married that we report. Some authors have shown that the lower prevalence of circulatory diseases or their risk factors among the married is restricted to those having a good marriage, whereas those in a poor marriage are in a worse position than the single $[51,62,63]$. With register data, it is of course impossible to consider the quality of the marriage. We also lacked data on other possibly relevant confounders, mediators or moderators such as lifestyle factors, values, prior health status or indicators of socio-economic status other than education.

Additionally, NorPD does not include drug purchases for individuals in health care institutions. Since the unmarried are more likely to be institutionalized, the actual use of medicine in this group may not be quite as modest compared to the married as indicated by our estimates. However, this bias must be small, as the analysis only includes persons younger than 80 , and at age 75-79 only $5 \%$ live in institutions [64].

An important strength of the study is availability of data that covers the whole population in which the measure of drug use was based on recorded purchase, assumed to be a good indicator of use, rather than selfreport of use.

\section{Conclusion}

Our results suggest that there is an underuse of medicine for circulatory disorders among the unmarried, and especially the never-married. The low usage of medication by the never-married particularly reflects low initial purchase of medication whereas for the divorced and widowed failure to continue with medication seemed more important. Inadequate use of these potentially very efficient medicines in such a large population group is, of course, a serious public health problem. Furthermore, underuse of medication for circulatory disorders among the unmarried in relatively recent years, combined with an increasing importance of such medicines, suggest a growing disadvantage for the unmarried when it comes to this type of medication (unless there was a much more pronounced underuse among these groups in earlier years, when the available medication was less efficient). This increasing disadvantage may have contributed to their falling behind with respect to mortality from circulatory diseases, and thus the widening marital status gap in all-cause mortality - which has been seen in a number of countries. In Norway, the excess mortality has increased particularly much for the group of unmarried also showing the clearest indications of underuse of medication for circulatory disorders, the never-married. Stated differently, the unmarried - and particularly the never-married- may not have benefited from recent life-saving improvements in medical treatment for circulatory disorders to the same extent as the married.

Further investigation of this issue is clearly warranted. A central element of such investigations should be to collect data that make it possible to better measure the potential underuse of medication. For that purpose, one would need information about the actual prevalence of the disorders as well as all types of treatment that are used. Obviously, it would also be an advantage if the data could shed light on the underlying mechanisms such as, for example, the role of spouses and children in prompting seeking of and adherence to treatment.

Competing interests

The authors declare that they have no competing interest.

\section{Authors' contributions}

Both authors have contributed to the planning of the analysis and the writing. $\varnothing \mathrm{K}$ has done the estimation. The final manuscript is approved by both authors.

\section{Acknowledgements}

The project is partly funded by an ERC Advanced Grant to Emily Grundy. The advice from Håkon Kravdal is greatly appreciated.

\section{Author details}

${ }^{1}$ Norwegian Institute of Public Health, Oslo, Norway. ${ }^{2}$ Department of Economics, University of Oslo, Oslo, Norway. ${ }^{3}$ Department of Social Policy, London School of Economics and Political Science, London, UK. ${ }^{4}$ Postal address: Department of Economics, P.O. Box 1095 Blindern, 0317 Oslo, Norway.

Received: 2 June 2014 Accepted: 24 October 2014

Published: 24 November 2014

\section{References}

1. Ben-Shlomo Y, Smith GD, Shipley M, Marmot MG: Magnitude and causes of mortality differences between married and unmarried men. J Epidemiol Community Health 1993, 47:200-205.

2. Joung IM, Glerum JJ, vanPoppel FW, Kardaun JW, Mackenbach JP, Glerum $J$ J, VanPoppel FW, Kardaun JW, Mackenbach JP: The contribution of specific causes of death to mortality differences by marital status in the Netherlands. Eur J Pub Health 1996, 6:142-149.

3. Rendall MS, Weden MM, Favreault MM, Waldron $\mathrm{H}$ : The protective effect of marriage for survival: a review and update. Demography 2011, 48:481-506. 
4. Brochmann $H$, Klein T: Love and death in Germany: the marital biography and its effect on mortality. J Marriage Fam 2004, 66:567-581.

5. Wilmoth J, Koso G: Does marital history matter? Marital status and wealth outcomes among preretirement adults. J Marriage Fam 2002, 64:254-268.

6. Umberson D, Montez JK: Social relationships and health: a flashpoint for health policy. J Health Soc Behav 2010, 51:S54-S66.

7. Lewis MA, Butterfield RM: Social control in marital relationships: effect of one's partner on health behaviors. J App/ Soc Psychol 2007, 37:298-319.

8. Fessler MT: Madmen: An Evolutionary Perspective on Anger and men's Violent Responses to Transgression. In International Handbook of Anger: Constituent and Concomitant Biological, Psychological, and Social Processes. Edited by Potegal M, Stemmler G, Speilberger C. New York: Springer; 2010:361-381.

9. Love DA: The effects of marital status and children on savings and portfolio choice. Rev Financ Stud 2010, 23:385-432.

10. Waite L, Gallagher M: Why Married People are Happier, Healthier, and Better Off Financially. New York: Broadway Books; 2002.

11. Hoffmann R, Plug I, McKee M, Khoshaba B, Westerling R, Looman C, Mackenbach JP: Innovations in medical care and mortality trends from four circulatory diseases between 1970 and 2005. Eur J Publ Health 2013, 23:852-857.

12. Lichtenberg FR: The impact of new drug launches on longevity: evidence from longitudinal, disease-level data from 52 countries, 1982-2001. Int J Health Care Finance Econ 2005, 5:47-73.

13. O'Flaherty M, Buchan I, Capewell S: Contributions of treatment and lifestyle to declining CVD mortality: why have CVD mortality rates declined so much since the 1960s? Heart 2013, 99:159-162.

14. Ford ES, Ajani UA, Croft JB, Critchley JA, Labarthe DR, Kottke TE, Giles WH, Capewll S: Explaining the decrease in U.S. deaths from coronary disease, 1980-2000. New Engl J Med 2007, 356:2388-2398.

15. Laatikainen T, Critchley J, Vartiainen E, Solomaa V, Ketonen M, Capewell S: Explaining the decline in coronary heart disease mortality in Finland between 1982 and 1997. Am J Epidemiol 2005, 162:764-773.

16. Capewell S, O'Flaherty M, Ford ES, Critchley JA: Potential reductions in United states coronary heart disease mortality by treating more patients. Am J Cardiol 2009, 103:1703-1709.

17. Berntsen KN: Trends in total and cause-specific mortality by marital status among elderly Norwegian men and women. BMC Public Health 2011, 11:537.

18. Murphy M, Grundy E, Kalogirou S: The increase in marital status differences in mortality up to the oldest age in seven European countries, 1990-99. Popul Stud 2007, 61:287-298.

19. Roelfs DJ, Shor E, Kalish $R$, Yogev $T$ : The rising relative risk of mortality for singles: meta-analysis and metaregression. Am J Epidemiol 2011, 174:379-389.

20. Atzema CL, Austin PC, Huynh T, Hassan A, Chiu M, Wang JT, Tu JV: Effect of marriage on duration of chest pain associated with acute myocardial infarction before seeking care. CMAJ 2011, 183:1482-1491.

21. Moser D, Kimble L, Alberts M, Alonzo A, Croft J, Dracup K, Evenson KR, Go AS, Hand MM, Kothari RU, Mensah GA, Morris DL, Pancioli AM, Riegel B, Zerwic JJ: Reducing delay in seeking treatment by patients with acute coronary syndrome and stroke: A scientific statement from the American Heart Association Council on cardiovasuclar Nursing and Stroke Council. Circulation 2006, 114:168-182.

22. Abdollah F, Sun M, Thuret R, Abdo A, Morgan M, Jeldres C, Shariat SF, Perrotte $P$, Montorsi F, Karakiewicz PI: The effect of marital status on stage and survival of prostate cancer patients treated with radical prostatectomy: a population-based study. Canc Causes Contr 2011, 22:1085-1095.

23. Ortiz CAR, Freeman JL, Kuo YF, Goodwin JS: The influence of marital status on stage at diagnosis and survival of older persons with melanoma. J Gerontol: Medical Sciences 2007, 62A:892-898.

24. Stimpson JP, Wilson FA: Cholesterol screening by marital status and sex in the United States. Preventing Chronic Disease 2009, 6:1-9.

25. Kulkarni SP, Alexander KP, Lytle B, Heiss G, Peterson ED: Long-term adherence with cardiovascular drug regimens. Am Heart J 2005, 151:185-191.

26. Marcum ZA, Zheng Y, Perera S, Strotmeyer E, Newman AB, Simonsick EM, Shorr Rl, Bauer DC, Donohue JM, Hanlon JT: Prevalence and correlates of self-reported medication non-adherence among older adults with coronary heart disease, diabetes mellitus, and/or hypertension. Res Soc Admin Pharm 2013, 9:817-827

27. Molloy GJ, Perkins-Porras L, Strike PC, Streptoe A: Social networks and partner stress as predictors of adherence to medication, rehabilitation attendance, and quality of life following acute coronary syndrome. Health Psychol 2008, 27:52-58.
28. Wu JR, Lennie TA, Chung ML, Frazier SK, Dekker RL, Biddle MJ, Moser DK: Medication adherence mediates the relationship between marital status and cardiac event-free survival in patients with heart failure. Heart \& Lung 2012, 41:107-114.

29. Trivedi RB, Ayotte B, Edelman D, Bosworth HB: The association of emotional wellbeing and marital status with treatment adherence among patients with hypertension. J Behav Med 2008, 31:489-497.

30. Simeonova E: Marriage, bereavement and mortality: the role of health care utilization. J Health Econ 2013, 32:33-50.

31. Gallagher $R$, Warwick M, Chenoweth L, Stein-Parbury J, Milton-Wildey K: Medication knowledge, adherence and predictors among people with heart failure and chronic obstructive pulmonary disease. $J$ Nurs Healthc Chronic IIIn 2011, 3:30-40.

32. Oksanen T, Kawachi I, Kouvonen A, Suzuki E, Takao S, Sjösten N, Virtanen M, Pentti J, Vahtera J, Kivimäki M: Workplace social contact and adherence to antihypertensive medication: a cohort study. PLOS One 2011, 6:e24732.

33. Furu K, Wettermark B, Andersen M, Martikainen JE, Almarsdottir AB, Sørensen HAT: The Nordic countries as a cohort for pharmacoepidemiological research. Basic Clin Pharmacol Toxicol 2011, 106:86-94.

34. Goldman N, Korenman S, Weinstein R: Marital status and health among the elderly. Soc Sci Med 1995, 40:717-730.

35. Williams K, Umberson D: Marital status, marital transitions, and health:a gendered life course perspective. J Health Soc Behav 2004, 45:81-98.

36. Lyngstad T, Jalovaara M: A review of the antecedents of union dissolution. Demogr Res 2010, 23:257-292.

37. Sweeney MM: Two decades of family change: the shifting economic foundations of marriage. Am Sociol Rev 2002, 67:132-147.

38. Elo IT: Social class differentials in health and mortality: patterns and explanations in comparative perspective. Annu Rev Sociol 2009, 35:553-572.

39. Vikum E, Bjørngaard JH, Westin S, Krokstad S: Socio-economic inequalities in Norwegian health care utilization over 3 decades: the HUNT Study. Eur J Pub Health 2013, 23:1003-1010.

40. Allison PD: Discrete-time methods for the analysis of event histories Sociol Methodol 1982, 13:61-98

41. Kuo RN, Dong YH, Liu JP, Chang CH, Shau WY, Lai MS: Predicting healthcare utilization using a pharmacy-based metric with the WHO's anatomical therapeutic chemical algorithm. Med Care 2011, 49:1031-1039.

42. Kamon Y, Okamura T, Tanaka T, Hozawa A, Yamagata Z, Takebayashi T, Kusaka Y, Urano S, Nakagawe H, Kadowaki T, Miyoshi Y, Yamato H, Okayama A, Ueshima H, the HIPOP.OHP Research Group: Marital status and cardiovascular risk factors among middle-aged Japanese male workers: The High-risk and Population Strategy for Occupational Health Promotion (HIPOP-OHP) Study. J Occup Health 2008, 50:348-356.

43. Molloy GJ, Stamatakis E, Randall G, Hamer M: Marital status, gender and cardiovascular mortality: behavioural, psychological distress and metabolic explanations. Soc Sci Med 2009, 69:223-228.

44. Choi BCK, Shi F: Risk factors for diabetes mellitus by age and sex: results of the national population health survey. Diabetologica 2001, 44:1221-1231.

45. Keenan NL, Rosendorf KA: Prevalence of hypertension and controlled hypertension - United States, 2005-2008. Morbidity and Mortality Weekly Report (Center for Disease Control) 2011, 60:94-97.

46. Lipowicz A, Lopuszanska M: Marital differences in blood pressure and the risk of hypertension among Polish men. Eur J Epidemiol 2005, 20:421-427.

47. Kamiya $Y$, Whelan B, Timonen $V$, Kenny RA: The differential impact of subjective and objective aspects of social engagement on cardiovascular risk factors. BMC Geriatr 2010, 10:81.

48. Ebrahim S, Wannamethee G, McCallum A, Walker M, Shaper AG: Marital status, change in marital status, and mortality in middle-aged British men. Am J Epidemiol 1995, 142:834-842.

49. Cubbin $C$, Sundquist $K$, Ahlén $H$, Johansson SE, Winkleby MA, Sundquist J: Neighborhood deprivation and cardiovascular disease risk factors: protective and harmful effects. Scand J Publ Health 2006, 34:228-237

50. Gallo LC, Troxel WM, Matthews KA, Kuller LH: Marital status and quality in middle-aged women: associations with levels and trajectories of cardiovascular risk factors. Health Psychol 2003, 22:53-463.

51. Gliksman MD, Lazarus R, Wilson A, Leeder SR: Social support, marital status and living arrangement correlates of cardiovascular disease risk factors in the elderly. Soc Sci Med 1995, 40:811-814. 
52. Engström G, Khan FA, Zia E, Jerntorp I, Pessah-Rasmussen H, Norrving B, Janzon L: Marital dissolution is followed by an increased incidence of stroke. Cerebrovasc Dis 2004, 18:318-324.

53. Maselko J, Bates LM, Avendano M, Glymour MM: The intersection of sex, marital status, and cardiovascular risk factors in shaping stroke incidence: results from the heath and retirement study. J Am Geriatr Soc 2009, 57:2293-2299.

54. Ingelsson E, Lind L, Ärnlöv J, Sundström J: Socioeconomic factors as predictors of incident heart failure. J Card Fail 2006, 12:540-545.

55. Yannakoulia M, Panagiotako D, Pitsavos C, Skoumas Y, Stafanadis C: Eating patterns may mediate the association between matrital status, body mass index, and blood cholesterol levels in apparently healthy men and women from the ATTICA study. Soc Sci Med 2008, 66:2230-2239.

56. Hedblad B, Jonsson S, Nilsson P, Engström G, Berglund G, Janzon L: Obesity and myocardial infarction - vulnerability related to occupational level and marital status. A 23-year follow-up of an urban male Swedish population. J Intern Med 2002, 252:542-550.

57. Bearden D, Allman R, McDonald R, Miller S, Pressel S, Petrovitch H: Age, race, and gender variation in the utilization of coronary artery bypass surgery and angioplasty in SHEP. SHEP cooperative research group. Systolic Hypertension in the Elderly Program. J Am Geriatr Soc 1994, 42:1143-1149.

58. Taylor FC, Huffman M, Ebrahim S: Statin therapy for primary prevention of cardiovascular disease. JAMA 2013, 310:2451-2452.

59. Ji R, Liu G, Shen H, Wang Y, Li H, Peterson E, Wang Y: Persistence of secondary prevention medications after acute ischemic stroke or transient ischemic attack in Chinese population: data from China national stroke registry. Neurol Res 2013, 35:29-36.

60. Floud S, Balkwill A, Canoy D, Wright FL, Reeves GK, Green B, Beral V, Cairns BJ, the Million Women Study Collaborators: Marital status and ischemic heart disease incidence and mortality in women: a large prospective study. BMC Med 2014, 12:42.

61. Statistics Norway: Living Arrangements in Norway. 2012. http://www.ssb.no/ english/subjects/02/01/20/samboer_en/.

62. Gallo LC, Troxel WM, Kuller LH, Sutton-Tyrrell K, Edmundowicz D, Matthews KA: Marital status, marital quality, and atherosclerotic burden in postmenopausal women. Psychosom Med 2003, 65:952-962.

63. Holt-Lunstad J, Birmingham W, Jones BQ: Is there something unique about marriage? The relative impact of marital status, relationship quality, and network social support on ambulatory blood pressure and mental health. Ann Behav Med 2008, 35:239-244.

64. Ugreninov E: Seniorer i Norge. Statistical Analyses 72. Oslo-Kongsvinger: Statistics Norway; 2005.

doi:10.1186/2050-6511-15-65

Cite this article as: Kravdal and Grundy: Underuse of medication for circulatory disorders among unmarried women and men in Norway? BMC Pharmacology and Toxicology 2014 15:65.

\section{Submit your next manuscript to BioMed Central and take full advantage of:}

- Convenient online submission

- Thorough peer review

- No space constraints or color figure charges

- Immediate publication on acceptance

- Inclusion in PubMed, CAS, Scopus and Google Scholar

- Research which is freely available for redistribution 